\title{
ULTRASOUND-ASSISTED EXTRACTION OF OIL FROM KIWIFRUIT (ACTINIDIA DELICIOSA) SEEDS
}

\author{
RENATA COELHO* \\ LUIS R. S. KANDA** \\ FABIANE HAMERSKI $I^{* * *}$ \\ ERIEL F. ANDRADE**** \\ MARIA LUCIA MASSON***** \\ MARCOS L. CORAZZA******
}

\begin{abstract}
This study reports experimental kinetic data and modeling for the extraction of oil from kiwifruit seeds by ultrasound-assisted extraction (UAE) with ethanol. The fatty acid profile, tocopherol and total lipids content in the oil obtained were determined. The variables temperature and ultrasonic power were investigated based on the oil extraction yields using a central composite experimental design. The overall yields obtained were compared to conventional Soxhlet extraction with $\mathrm{n}$-hexane and with ethanol. The extractions presented high extraction rates with overall yield ranged between 19 and $33 \%$, and the extraction yields increased with the temperature. The fatty acid profile showed a high content of omega- 3 fatty acids $(63.20 \%)$ and the Vitamin E content was $14.97 \pm 0.38 \mathrm{mg} / 100 \mathrm{~g}$ oil, with $\gamma$-tocopherol constituting $49 \%$ of the total tocopherol. A secondorder kinetic model was applied to describe the ultrasound extraction process under different conditions. The numerical results were compared with the experimental extraction yields and presented a good correlation. The extraction technique investigated was found to be suitable for extraction of oil from kiwifruit seeds, in which the great potential of kiwifruit oil obtained from UAE was demonstrated.
\end{abstract}

KEYWORDS: KIWIFRUIT SEED OIL, KINETIC MODEL, ULTRASOUND-ASSISTED EXTRACTION, CHEMICAL CHARACTERIZATION.

${ }^{*}$ Corresponding author: Dr. Marcos L. Corazza, Department of Chemical Engineering, Federal University of Paraná, PO Box 19011 Polytechnic Center, Curitiba 81531-980, PR, Brazil. Email: corazza@ufpr.br 


\section{INTRODUCTION}

Alternative methods of vegetable oils extraction have been largely explored, especially those employing techniques that are efficient, environmentally friendly, and that minimize the waste generation as well as the presence of toxic residues in the final products. Concerning oil extraction processes, nowadays, the natural character of obtainment of vegetable oils has a high marketing value (De Melo et al., 2014). In the meantime, development in high-intensity ultrasound technology has increased its use in several industries (Abdullah and Koc, 2013). Ultrasound-assisted extraction (UAE) is a solvent extraction technique that has been widely studied and it can enhance the extraction efficiency by reducing the extraction time, as well as the energy and solvent consumption (Fang et al., 2014; Goula, 2013; Shalmashi, 2009). Extraction enhancement by ultrasound can be attributed to the propagation of ultrasound pressure waves and resulting cavitation forces, where bubbles can explosively collapse and generate localized pressure causing ruptures in the plant tissue and improving the release of intracellular substances into the solvent (Goula, 2013; Knorr et al., 2002). Abdullah and Koc (Abdullah and Koc, 2013) has studied a ultrasound-assisted oil extraction from black seed and reached a maximum oil efficiency of $67.94 \%$ (mass of extracted oil per mass of total oil content of ground black seed) at $32{ }^{\circ} \mathrm{C}$, solvent to seed ratio of $20: 1(\mathrm{w} / \mathrm{w})$ and extraction time of 30 minutes. They concluded that the use of a high intensity ultrasound in oil extraction processes reduced the oil extraction time by enhancing the oil extraction rates during the diffusion stage. Some studies also found that UAE requires a significant shorter time and reduced solvent consumption (Shalmashi, 2009; Zhang et al., 2008). In the study of Zen-Shan Zhang et al (Zhang et al., 2008), the extraction yields of flaxseed oil increased with the increase of ultrasonic power and decreased as the temperature was increased. The best conditions were found to be ultrasonic power of $50 \mathrm{~W}$, temperature of $30^{\circ} \mathrm{C}$ and extraction time of $30 \mathrm{~min}$, with a liquid to solid ratio of $6: 1(\mathrm{w} / \mathrm{w})$. A study using response surface methodology to optimize the parameters affecting UAE of seed oil from Isatis indigotica showed that the temperature used in the extractions plays the most important role, whereas the influence of other variables was less, in the following order: particle size, solvent to sample ratio and extraction time (Li et al., 2012).

The kiwifruit is an edible berry, and the most common variety commercially available is a cultivar that belongs to the Actinidia deliciosa species (Fiorentino et al., 2009). Oil from kiwifruit seeds has a very interesting fatty acid profile, with a high level of C18:3n3, reflecting in a very low ratio of $\mathrm{n}-6 / \mathrm{n}-3$. In human diet, the consumption of $\mathrm{n}-6$ fatty acids compared with $\mathrm{n}-3$ should be limited when considering the prevention of cancers, heart diseases, hypertension and autoimmune disorders (Van Hoed et al., 2009). Kiwifruit seed oil is a kind of functional health oil with properties that could justify its commercialization at high prices. Some of the health benefits that may be associated with oils rich in C18:3n3 include lower risks of inflammation, autoimmune diseases, coronary heart disease, cancer, depression and improvements in cholesterol (Lespérance et al., 2011; Simopoulos, 2002).

Vegetable oil seeds are traditionally obtained by solvent extraction with n-hexane or coldpressing method. The solvent extraction with $n$-hexane can lead to possible toxic solvent residue in the oil. At cold-pressing processes with seeds, the temperature inevitably increases during the pressing process, due to friction (Van Hoed et al., 2009).

This study deals with the extraction of oil from seed of kiwifruits waste using ultrasoundassisted extraction with ethanol as the solvent. The extraction yields obtained, chemical fatty acid profile and total lipids of the extracted oil were determined and compared to conventional Soxhlet extraction using n-hexane and ethanol as solvents. This study proposes a contribution on the investigation of alternative extraction techniques to obtain oil from kiwifruit seeds throughout the use of high-intensity ultrasound technology and a green solvent (ethanol). 


\section{MATERIALS AND METHODS}

\subsection{KIWIFRUIT SEEDS}

The kiwifruit seeds were obtained from an organic fruits farm in Cerro Negro, State of Santa Catarina, Brazil. Around 100 rape fruits were collected, mashed and submerged in a solution of $5 \mathrm{~L}$ of water and $1 \mathrm{~mL}$ of diluted pectinase $(1: 200 \mathrm{v} / \mathrm{v})$ and left for $2-3$ days at room temperature $(293.15$ to $298.15 \mathrm{~K}$ ). The resulted pulp and seeds were place on a sieve and washed with distilled water in order to remove any adhering materials from the seeds. After that, the seeds were dried at $333.15 \mathrm{~K}$ for $24 \mathrm{~h}$ until final moisture content of $5.4 \mathrm{wt} \%$, and thereafter vacuum packaged and kept at $255.15 \mathrm{~K}$ until its use. The kiwifruit seeds were ground in a laboratory mill immediately prior to the extractions.

\subsection{ULTRASOUND-ASSISTED EXTRACTION WITH ETHANOL}

The ethanol used, with a purity of $>99.5 \mathrm{wt} \%$, was supplied by Neon (São Paulo, Brazil) and it was used without further purification.

An ultrasound bath (Unique, São Paulo, Brazil, model Q59/37A), with nominal power of $163 \mathrm{~W}, 37 \mathrm{kHz}$, was used for the ultrasound-assisted extractions. The ultrasonic power control was allowed to set at any desired level ranged within 0 (without ultrasonic irradiation) to $99 \%$ of the nominal power.

Sealed vials ( $40 \mathrm{~mL}$ of capacity) with the milled seeds and ethanol were placed in the ultrasound bath with the temperature and the ultrasonic-power set as defined in the factorial experimental design $2^{2}$ (Table 1), with a triplicate at the central point. Some preliminary tests were carried out to define the optimum seed to ethanol ratio $(\mathrm{w} / \mathrm{w})$, and the optimum ratio obtained was used for all experiments.

All kinetic extractions were performed in a batch mode using the same procedure described. The ultrasonic-power and temperature were kept constant and the extractions were ended at $0.5,1$, $3,5,10,20,30,40,50$ and $60 \mathrm{~min}$. The resulted solutions were filtered and the solvent removed by rotary evaporating (IKA, RV 10). After that, the samples were dried at $333.15 \mathrm{~K}$ in a circulation oven until constant weight to remove any residual ethanol. The extracted oil mass was gravimetrically determined (BEL Engineering, Mark Serie M 250A).

TABLE 1 - EXPERIMENTAL CONDITIONS OF COMPLETE FACTORIAL DESIGN $\left(2^{2}\right)$ USED FOR KIWIFRUIT SEED EXTRACTIONS WITH ETHANOL AND RESULTS OF EXTRACTION YIELD AT 60 MIN OF EXTRACTION.

\begin{tabular}{cccc}
\hline Experiment & Temperature (K) & $\begin{array}{c}\text { Percentage of ultrasonic } \\
\text { power (USP\%)* }\end{array}$ & Oil yield \% (w/w) \\
\hline 01 & 293.15 & 49 & $19.51^{\mathrm{bc}}$ \\
\hline 02 & 333.15 & 49 & $24.56^{\mathrm{b}}$ \\
\hline 03 & 293.15 & 99 & $19.22^{\mathrm{c}}$ \\
\hline 04 & 333.15 & 99 & $33.55^{\mathrm{a}}$ \\
\hline $05^{* *}$ & 313.15 & 74 & $23.14 \pm 1.92^{\mathrm{bc}}$ \\
\hline
\end{tabular}

*Related to nominal ultrasonic power $(163 \mathrm{~W})$

** Average \pm standard deviation of oil yield extraction considering the triplicate at central point.Values followed by the same superscript letters are not significantly different from each other by the Tukey's test $(\mathrm{p}>0.05)$.

The results of oil extraction were statistically analysed by using the software Statistica 7.0 (Analytical Software, Tallahassee, FL, USA). ANOVA was used to evaluate the effect of variables 
studied in the oil extractions. Tukey's test was used to assess differences between means considering $p$-values of less than $0.05(p<0.05)$ as statistically significant.

\subsection{SOXHLET EXTRACTION WITH ETHANOL}

Soxhlet extractions with ethanol were carried out according to the method adapted from AOAC (Horwitz and Latimer, 2005), in triplicate, using a Soxhlet extraction apparatus (Nova Etica, Brazil). Ethanol (> $99.5 \mathrm{wt} \%$ purity) was supplied by Neon (São Paulo, Brazil) and it was used without further purification. Around $5 \mathrm{~g}$ of dried seeds were loaded into the main chamber of the Soxhlet apparatus and extracted for 6 hours.

\subsection{KINETIC MODELLING}

Considering the studies that aim to describe the mechanisms and kinetics of the extraction processes, many researchers propose a second-order reaction kinetics for the solid-liquid extraction (Saxena et al., 2011). This kinetic model is obtained from the mass rate transfer balance and it is integrated as represented by the following equation.

$$
C=\frac{C e^{2} \cdot k \cdot t}{1+C e \cdot k \cdot t}
$$

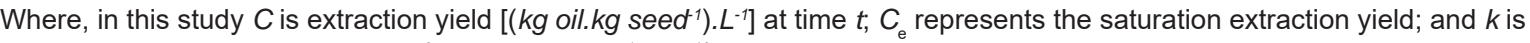
the second-order kinetic constant ( $\mathrm{kg}$ seed. L. $\left.\mathrm{kg} \mathrm{oil}{ }^{-1} \cdot \mathrm{min}^{-1}\right)$.

The experimental overall extraction yield, expressed as $\left[\left(\mathrm{kg}_{\text {oil }} / \mathrm{kg}_{\text {seed }}{ }^{-1}\right) \cdot \mathrm{L}^{-1}\right]$ (that means mass of oil extracted divided by mass of raw material and divided by volume of solvent used) versus time, were used to adjust the kinetic parameters by minimizing the mean square difference between experiments and calculated values, using the tool Solver MS-Excel (MS Office $3600^{\circ}$ ). The quality fitting was evaluated by the root mean square deviation $(r m s d)$ and the coefficient of determination $\left(R^{2}\right)$.

\subsection{TOTAL LIPIDS ANALYSIS}

The total lipids content of kiwifruit seeds and to all samples of extracts were determined in accordance to the Bligh \& Dyer method (Bligh and Dyer, 1959). This method is based on optimum of lipid extraction that the sample is homogenized with a mixture of chloroform and methanol. The total oil content in the kiwifruit seeds $\left(C L_{s}\right)$ was 33.69 (wt\%) (Coelho et al., 2015); and the total lipids content of the extracts $\left(C L_{E}\right)$ were determined for all samples obtained.

\subsection{GAS CHROMATOGRAPHY ANALYSIS OF FATTY ACID PROFILE}

The fatty acid profile of the oil extracted was determined by gas chromatography, in terms of the fatty acid methyl esters profile (FAMEs), according to the AOCS Official Method Ce 2-66 (Horwitz and Latimer, 2005), in a Varian gas chromatograph (model CP 3900), equipped with flame ionization detector (CG-FID) and equipped with a fused-silica capillary column (CP-SIL 88 CB; 100 $\mathrm{m} \times 0.25 \mathrm{~mm} \times 0.2 \mu \mathrm{m}$ ). The carrier gas was nitrogen (White Martins S.A., P.A., chromatographic grade). The injector and detector temperatures were $533.15 \mathrm{~K}$ and $573.15 \mathrm{~K}$, respectively. The following schedule was used: initial temperature of $413.15 \mathrm{~K}$ for 40 minutes ramped to $513.15 \mathrm{~K}$ at a $2 \mathrm{~K} \mathrm{~min}^{-1}$ rate, the split ratio of $1: 100$ and nitrogen flow rate $2.0 \mathrm{~mL} \mathrm{~min}^{-1}$. Sample preparation was performed by injection of a single dilution of the extract in $n$-hexane (chromatographic grade). FAMEs were identified by comparison with the standard FAMEs (Supelco, MIX FAME 37) and quantified as percentages of total methyl ester peak areas. 


\subsection{CONTENT OF TOCOPHEROLS ANALYSIS}

\subsubsection{Sample preparation}

The kiwifruit seeds oil samples were first submitted to a sequence of extraction and tocopherol concentration steps based on the methodology proposed by Tasioula-Margari and Okogeri (TasioulaMargari and Okogeri, 2001). All the following procedures described hereafter were performed in triplicate, avoiding the samples exposure to the light. The samples, with about $2 \mathrm{~g}$ of the kiwifruit seed oil, were placed into a $12 \mathrm{~mL}$ amber glass vial with $4 \mathrm{~mL}$ of methanol $(99.9 \%$ purity - Panreac, São Paulo, Brazil). The resulting solution was shaken and left to sediment until phase separation occurs (nearly 20 minutes). The methanolic phase was collected and $4 \mathrm{~mL}$ of pure methanol were added again into the vial leading to a new extraction step. The procedure was repeated 4 times and the methanolic phases collected in each step were joined and then concentrated by rotary evaporation (IKA-RV10), at $303.15 \mathrm{~K}$ and $350 \mathrm{mmHg}$ until complete removal of solvent. The extract material was diluted in $2 \mathrm{~mL}$ of isopropanol (purity of $>99.9 \%$, Panreac, São Paulo, Brazil) and the solution was analysed by high performance liquid chromatography (HPLC) for tocopherol determination.

\subsubsection{HPLC analysis of tocopherols}

The tocopherols determinations were performed on Agilent 1200 Series high performance liquid chromatograph (HPLC) equipped by quaternary pump, automatic liquid sampler and diode arrangement detector (DAD). Separations were performed by the use of a Kinetex - C18 column (4.6 x $150 \mathrm{~mm}, 5 \mu \mathrm{m})$, the mobile phase composed by methanol and 2-propanol $(90: 10, \mathrm{v} / \mathrm{v})$, the pump flow rate was $1 \mathrm{ml}$. min ${ }^{-1}$ and the injection volume was $20 \mu \mathrm{L}$. The detection was performed at $292 \mathrm{~nm}$ for all analysed tocopherols, with each run interval of $7 \mathrm{~min}$.

The tocopherols were identified by comparison between retention time of the sample compounds and retention time of standards of the $\alpha-, \gamma$ - and $\delta$-tocopherols (obtained from Sigma, 99 $\%$ of purity). Additionally, the DAD device was used to identify the compounds on the peak basis of their absorption spectra.

The tocopherols quantification was performed by external calibration with calibration curves of standard solutions of $\alpha-, y$ - and $\delta$-tocopherol $\left(0.5-50 \mathrm{mg} \cdot \mathrm{L}^{-1}\right)$. The total tocopherol content was expressed as milligrams per 100 gram oil.

\subsection{SCANNING ELECTRON MICROSCOPY}

The images of the seeds surface were produced by a Tescan VEGA3 LMU scanning electron microscope. For the analysis, the sample required special preparation, so it was coated in ultrathin gold by an SCD 030 Balzers Union FL 9496 Balzers equipment.

\section{RESULTS AND DISCUSSION}

Kiwifruit seed to ethanol mass ratio (\%) was investigated attempting to find better ratio to maximize the extraction yield in the ultrasound-assisted extraction. This evaluation was performed at fixed conditions of $333.15 \mathrm{~K}, 0 \%$ and $99 \%$ related to the nominal power of ultrasound and $60 \mathrm{~min}$ of extraction. These results are showed in Figure 1. The results indicated that the best oil extraction yield (around 30\% ) was obtained with a kiwifruit seed to ethanol mass ratio not exceeding $5 \%(\mathrm{w} / \mathrm{w})$. Furthermore, with a kiwifruit seed to ethanol mass ratio of $5 \%$ the yield obtained was around the same obtained for the extraction at $2 \%$. It was observed that the extraction yield in ultrasound bath decreased with kiwifruit seed to ethanol mass ratios greater than $5 \%(10 \%, 15 \%$ and $20 \%)$, possibly because the solvent phase was saturated, due to the limited vegetable oil solubility in ethanol. From these results, the extractions in the ultrasound bath were performed with the ratio of $5 \%$ of seed/ ethanol $(\mathrm{w} / \mathrm{w})$, following the experimental design presented in Table 1. 


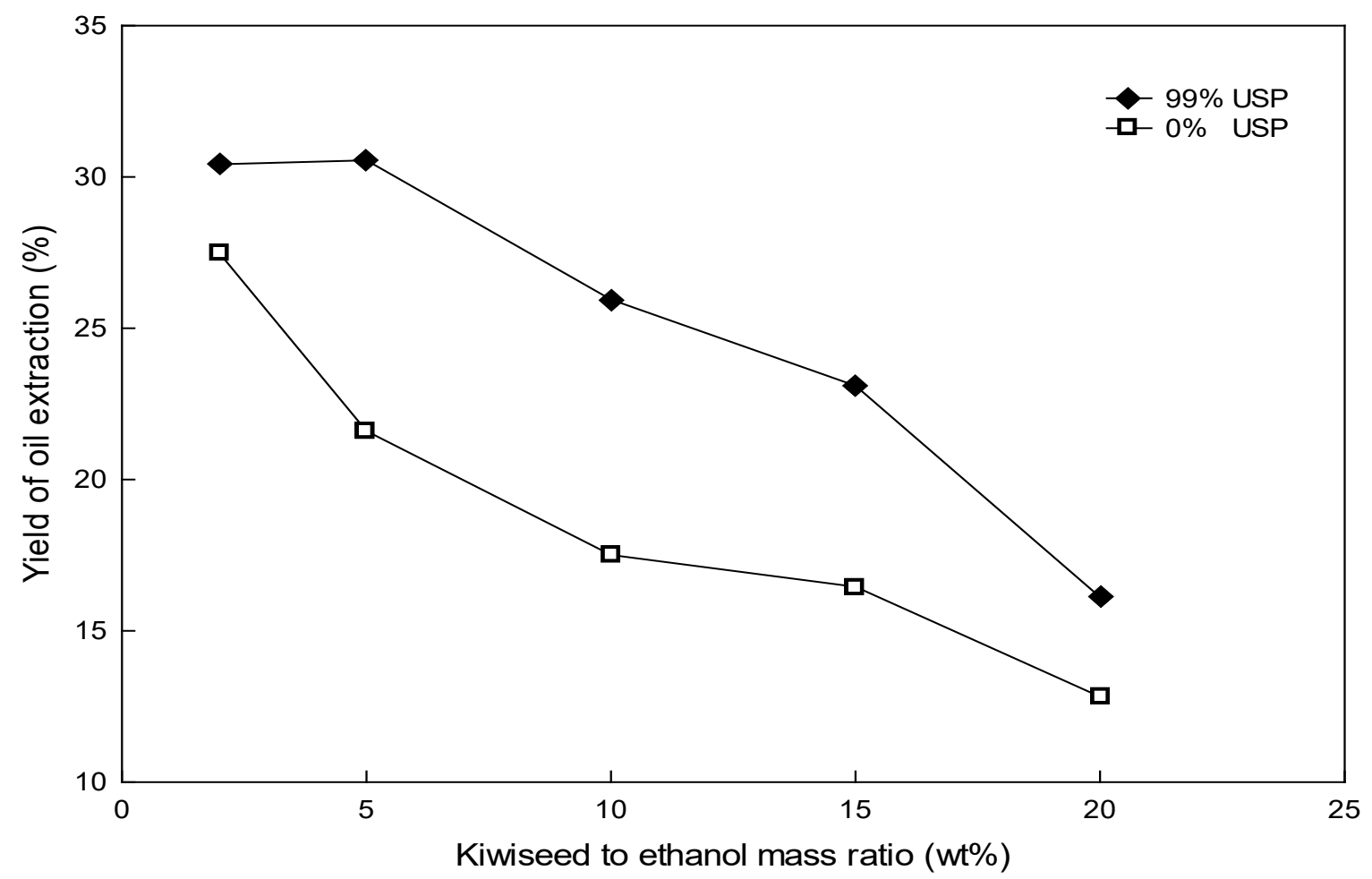

\section{FIGURE 1 - EFFECT OF KIWIFRUIT SEEDS TO ETHANOL MASS RATIO (WT\%) IN THE EXTRACTION YIELD, AT $60^{\circ} \mathrm{C}$ AND 30 MIN OF EXTRACTION.}

The temperature and ultrasound power (USP\%) effects were evaluated in terms of oil extraction from kiwifruit seeds using the ultrasound-assisted extraction technique with ethanol. The experimental results obtained according to the experimental design conditions are also showed in Table 1. The statistical analysis indicated that, according to the Paretto test (Figure 2), the temperature showed a significant and positive effect on the extraction yields. It can be seen that in the experiments performed at the highest temperature in this study $(333.15 \mathrm{~K})$, higher amount of oil was extracted. The condition of extraction that led to a higher extraction yield (33.55\%) was obtained with the association between the highest temperature $(333.15 \mathrm{~K})$ and the highest percentage of ultrasound power $(99 \%)$. In the experiments at the lowest temperature $(293.15 \mathrm{~K})$, no differences of extraction yield values were observed by changing the ultrasound power, and the maximum yield obtained was $19.51 \%$.

The maximum oil extraction yield (around 33.55\%) obtained by extraction with ethanol in the ultrasound-assisted process was similar to the yield obtained by the traditional Soxhlet extraction with n-hexane (33.52 $\pm 1.02 \%$ ) (Coelho et al., 2015), and Soxhlet extraction with ethanol (31.15 $\pm 0.37 \%$ ). However, it is worth mentioning that the ultrasound-assisted allows a decrease of the extraction time up to $60 \mathrm{~min}$, as presented in the present study. 


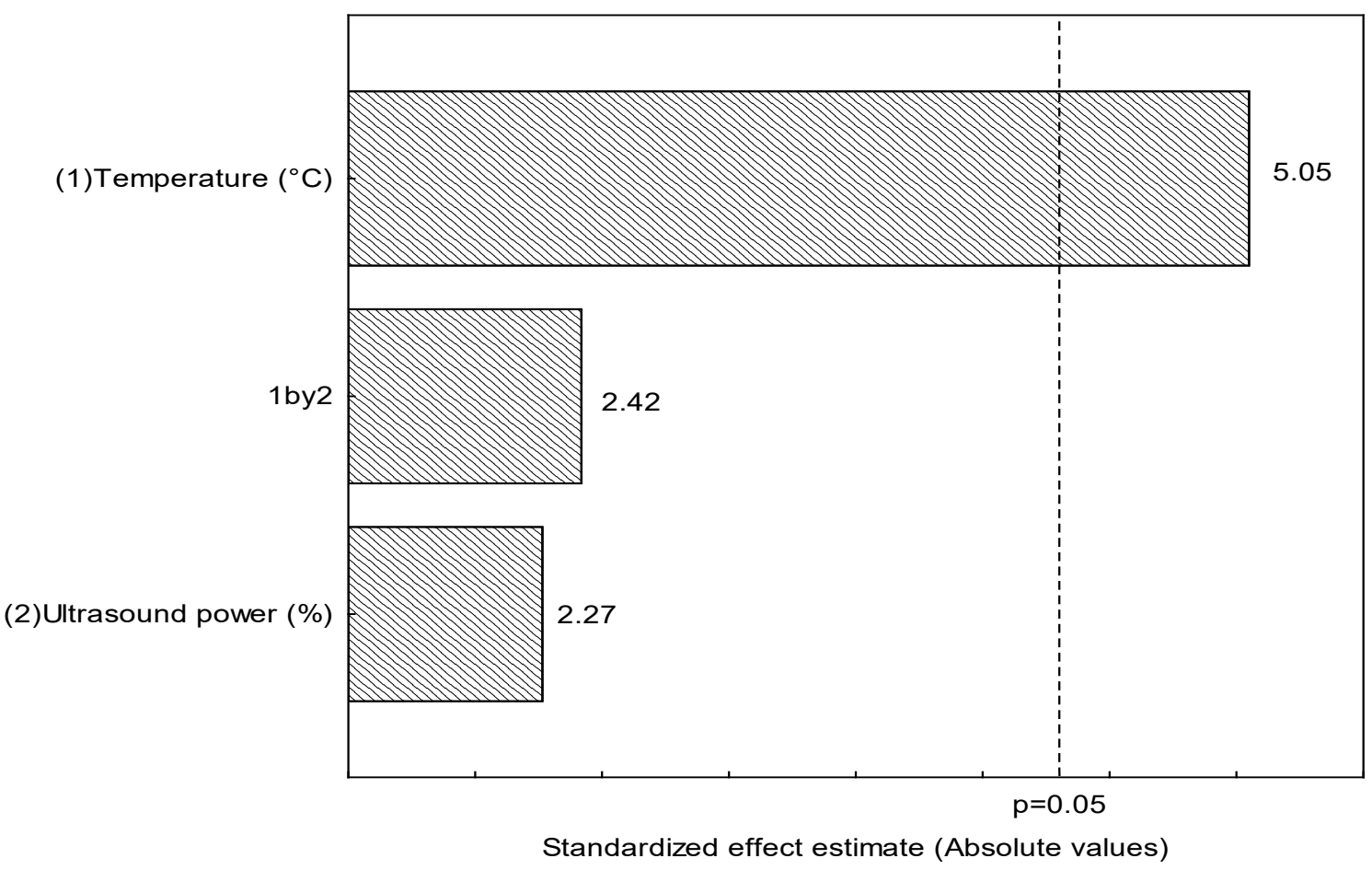

\section{FIGURE 2 - PARETO CHART OF STANDARDIZED EFFECTS OF EXPERIMENTAL DESIGN} 22 FOR THE ULTRASOUND-ASSISTED EXTRACTIONS.

Figure 3 depicts the experimental and calculated values using the kinetic model adjusted considering each experimental condition evaluated. The kinetic model was able to correlate the experimental results of kiwifruit seed oil extraction in an ultrasound-assisted technique with ethanol at different conditions, as it can be observed through this figure as well as based on the root mean deviation $(r m s d)$ and the coefficient of determination $\left(R^{2}\right)$, presented in Table 2. For every kinetic curve, the initial period of extraction were similar between all conditions and presenting very high initial rates of mass transfer, when the fresh extracting solvent is in contact to the seed surface region of the solid in a high concentration gradient condition. In the next stage, the extraction rate is slowed down by the low diffusion of the remaining oil.

TABLE 2 - FITTED PARAMETERS FOR SECOND ORDER KINETIC MODEL AT DIFFERENT TEMPERATURES AND ULTRASOUND POWER (USP\%).

\begin{tabular}{|c|c|c|c|c|c|}
\hline $\mathrm{T}(\mathrm{K})$ & USP\% & $\begin{array}{c}C e \\
\left.\text { (kg oil.kg seed }{ }^{-1} \cdot L^{-1}\right)\end{array}$ & $\begin{array}{c}k \\
\left(\mathrm{~kg} \text { seed.L.kg oil }{ }^{-1} . \mathrm{min}^{-1}\right)\end{array}$ & rmsd & $R^{2}$ \\
\hline \multirow[t]{2}{*}{293.15} & 49 & 5.85 & 0.2079 & 0.34 & 0.9686 \\
\hline & 99 & 7.14 & 0.1913 & 0.49 & 0.9535 \\
\hline \multirow[t]{2}{*}{313.15} & 0 & 7.31 & 0.2372 & 0.34 & 0.9776 \\
\hline & 74 & 8.23 & 0.2546 & 0.64 & 0.9391 \\
\hline \multirow[t]{3}{*}{333.15} & 0 & 7.03 & 0.2906 & 0.16 & 0.9752 \\
\hline & 49 & 7.63 & 0.2948 & 0.30 & 0.9839 \\
\hline & 99 & 9.51 & 0.3085 & 0.61 & 0.9564 \\
\hline
\end{tabular}


It can be seen that after the first 10 min of extraction, the oil extraction yields practically did not change for all experimental conditions, except in extraction performed at $333.15 \mathrm{~K}$ and $99 \%$ of ultrasound nominal power, where we observe a continuous increasing in the extraction yield and, after $60 \mathrm{~min}$, the maximum extraction yield was obtained. Probably the highest temperature $(333.15 \mathrm{~K})$ associated with highest ultrasound power (99\%) contributed to the oil miscibility in ethanol and improved the oil extraction.
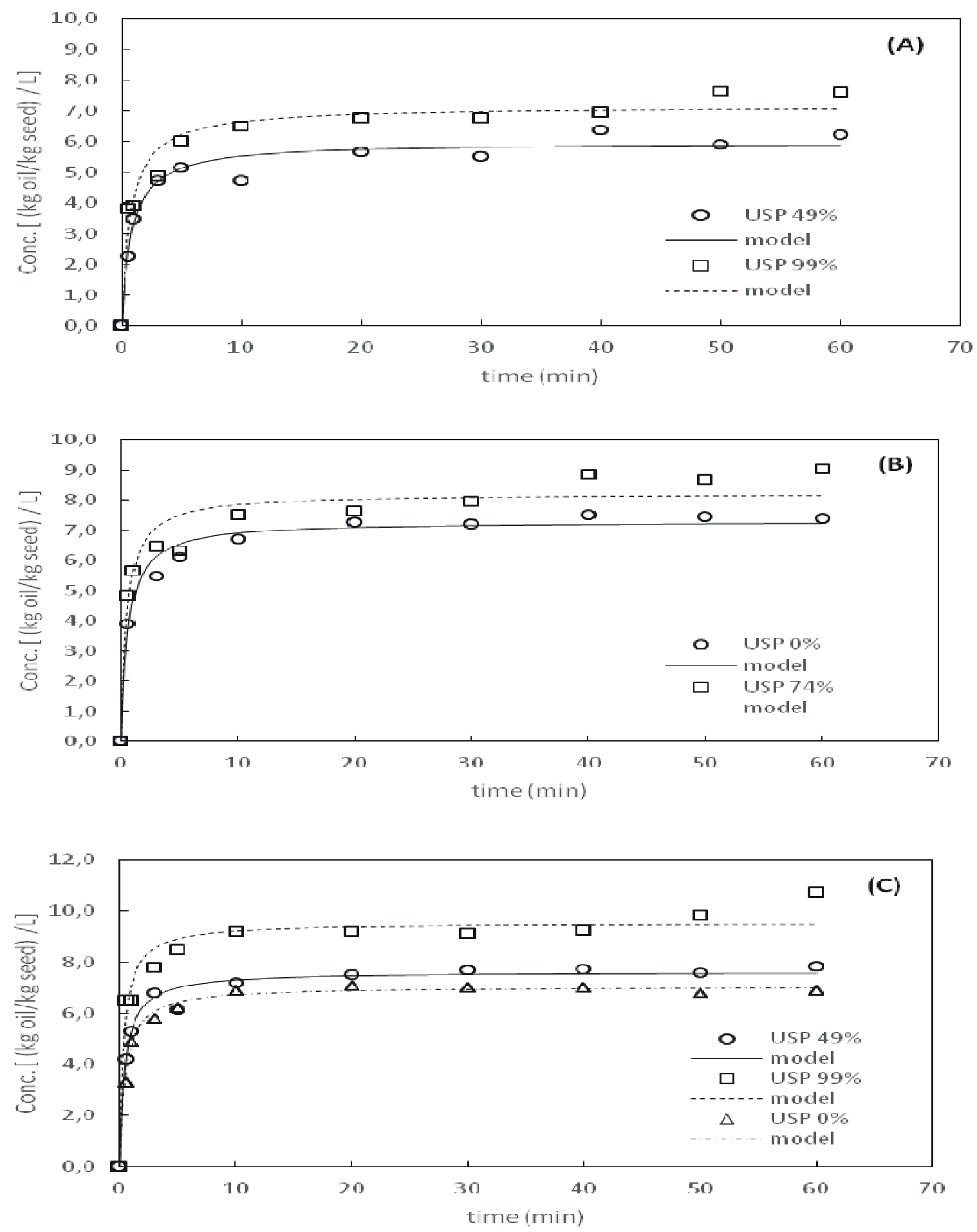

FIGURE 3 - EXPERIMENTAL AND KINETIC MODELING OF EXTRACTION CURVES OF KIWISEED OIL USING A ULTRASOUND-ASSISTED EXTRACTION AT (A) $293.15 \mathrm{~K}$; (B) 313.15 K AND (C) 333.15 K AND DIFFERENT ULTRASONIC POWER (USP \%). 
At low temperatures, the maximum oil extraction yield was not obtained, probably due to difficulties of oil desorption, mass transfer or to the reduced miscibility of oil in ethanol at these conditions, even with the use of ultrasound to attempt better perform the extraction.

Another important consideration observed in this work is that the extractions of kiwifruit seed oil, by UAE with ethanol and the extraction in Soxhlet, presented high extraction yields when the kiwifruit seeds were milled. In this study, we also evaluated the oil extractions with whole seeds. For UAE, after $60 \mathrm{~min}$ of extraction with whole seeds, performed at $313.15 \mathrm{~K}$ and $74 \%$ of ultrasound power (conditions of central point of experimental design), we have obtained only $1.3 \%$ of oil extraction yield. These results are showing that the shell of kiwifruit seed plays an important whole in the mass transfer limitations in the system. For assuring the maximum extraction yields, the seed must be ground. The micrographic images of a kiwifruit seed using scanning electron microscopy (SEM) are shown in Figure $4(a-b)$. It can be observed that the kiwifruit seed shell presents no pores (Figure 4(a)). In the sliced kiwifruit seed image, Figure 4(b), the inner part presents cavities where the oil is stored. When the seed structure is broken during the milling process, the oil is readily available and easily extracted in any compatible solvent. These characteristics justify the high extraction rates obtained using UAE with ethanol and milled kiwifruit seeds.

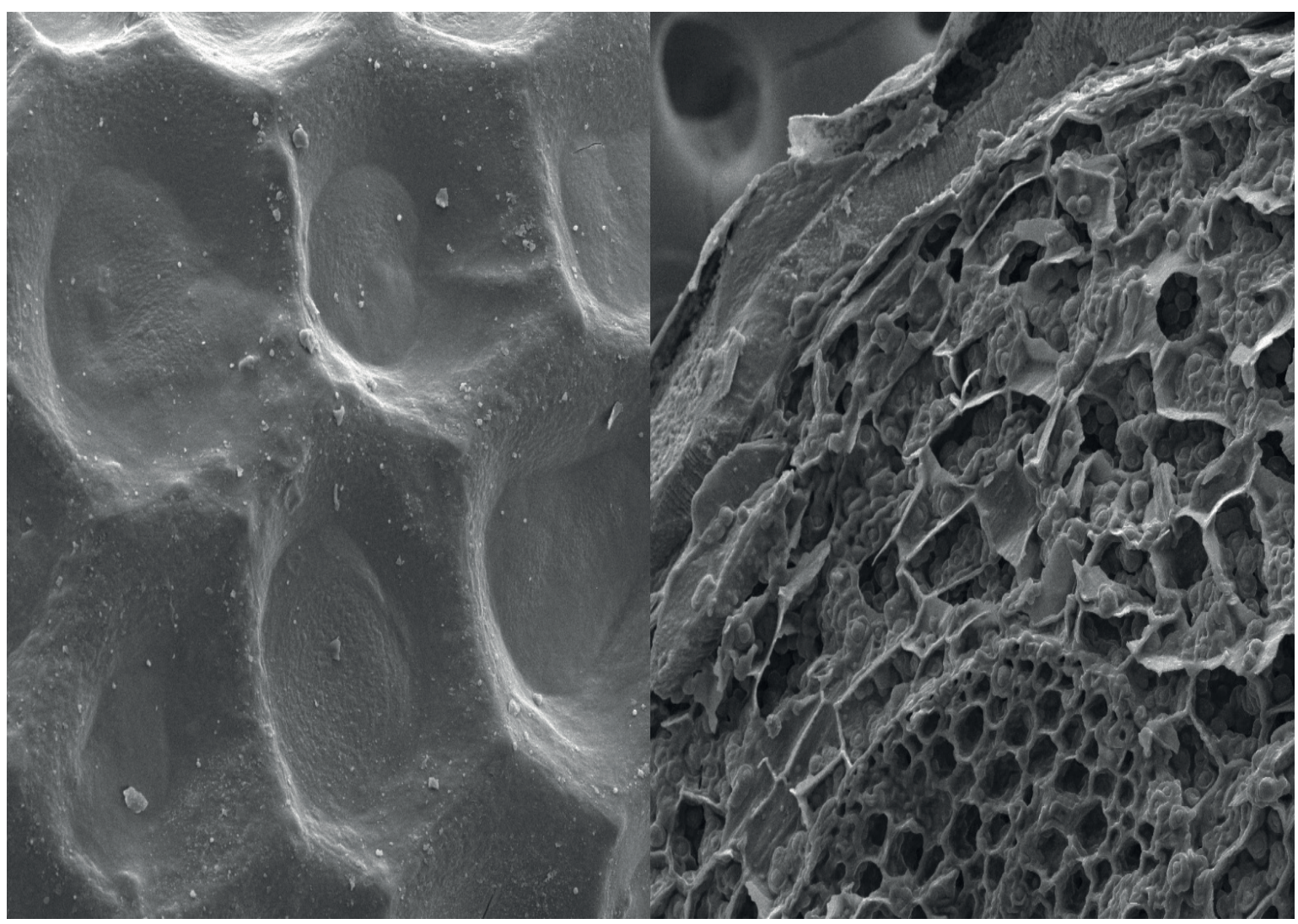

FIGURE 4 - SEM IMAGE OF KIWIFRUIT SEED (A) SURFACE OF WHOLE SEED (B) INTERNAL STRUCTURE OF KIWIFRUIT SEED.

\subsection{FATTY ACID COMPOSITION OF THE EXTRACTS}

The content of total lipids for different samples of extracted oil by UAE (Table 3) were compared to the results obtained by Soxhlet and also compared to the previous results of extraction using compressed propane as solvent, as presented in the literature (Coelho et al., 2015), in which the oil obtained from different extraction techniques presented basically the same total lipids. These results are showing that the ultrasound-assisted extraction using ethanol as solvent presented the 
same efficiency and selectivity, when compared to other extraction techniques and it is a promising tool for extraction of this oilseed agro-product.

\section{TABLE 3 - FATTY ACID COMPOSITION (\% OF TOTAL FATTY ACIDS) OF KIWIFRUIT SEED OIL EXTRACTED BY DIFFERENT METHODS AND CONTENT OF TOTAL LIPIDS}

\begin{tabular}{cccccccc}
\hline Method & $\mathbf{C 1 8 : 3 n 3}$ & $\mathbf{C 1 8 : 3 n 6}$ & $\mathbf{C 1 8 : 2 n 6 C}$ & $\mathbf{C 1 8 : 1 n 9 c}$ & $\mathbf{C 1 8 : 0 0}$ & $\mathbf{C 1 6 : 0}$ & Total Lipids (\%) \\
Soxhlet & $64.63^{\mathrm{a}}$ & $0.35^{\mathrm{a}}$ & $12.49^{\mathrm{b}}$ & $14.17^{\mathrm{a}}$ & $3.20^{\mathrm{a}}$ & $4.90^{\mathrm{b}}$ & $98.50^{\mathrm{a}} \pm 0.56$ \\
UAE & $63.20^{\mathrm{a}}$ & - & $13.27^{\mathrm{ab}}$ & $14.75^{\mathrm{a}}$ & $3.31^{\mathrm{a}}$ & $5.29^{\mathrm{a}}$ & $91.39^{\mathrm{c}} \pm 1.75$ \\
$\begin{array}{c}\text { Compressed } \\
\text { propane }\end{array}$ & $63.40^{\mathrm{a}}$ & $0.36^{\mathrm{a}}$ & $13.51^{\mathrm{a}}$ & $14.42^{\mathrm{a}}$ & $3.34^{\mathrm{a}}$ & $5.24^{\mathrm{a}}$ & $95.76^{\mathrm{b}} \pm 1.39$ \\
Standard deviation & 1.31 & 0.02 & 0.02 & 0.96 & 0.07 & 0.08 \\
Means followed by the same letter, in the same column, are statistical identical by the Tukey test (p>0.05). \\
* Coelho et al. (2015)
\end{tabular}

In the same way, the fatty acids profiles was practically the same concerning the different extraction methods used (Table 3). Some previous studies have shown that changes in extraction conditions and solvent type did not substantially lead to differences on the fatty acid composition of the extracts (Hamdan et al., 2008; Illés et al., 2000; Pederssetti et al., 2011). From the fatty acid profile, it can be observed that kiwifruit seed oil is very interesting from a nutritional point of view. All samples showed a very high proportion (superior of $60 \%$ ) of linolenic acid (C18:3). The kiwifruit seed oil were composed by $95 \%$ of saturated and unsaturated C:18 fatty acids.

The total tocopherol content of kiwifruit seed oil extracted by UAE with ethanol was $14.97 \pm$ $0.38 \mathrm{mg} / 100 \mathrm{~g}$ oil. The $\gamma$-tocopherol constitutes $49 \%$ of the total tocopherol with $7.31 \pm 0.19 \mathrm{mg} / 100$ $\mathrm{g}$ oil. The results for $\delta$-tocopherol and $\alpha$-tocopherol were $5.74 \pm 0.03$ and $1.91 \pm 0.13 \mathrm{mg} / 100 \mathrm{~g}$ oil, respectively.

The total tocopherol content found in this work was comparable to the value of tocopherol content of oil seeds found in the literature (MatthauS and Ozcan, 2011; Stevenson et al., 2007), but it is worth mentioning that the literature shows a wide range of total tocopherols values for vegetable oil from seeds.

In a general way, from the results obtained in this work, it is seemed that the oil from kiwifruit seeds can be aimed to a noble use in food, nutraceutical, pharmaceutical and cosmetic industries formulations.

\section{CONCLUSIONS}

Based on the findings, when compared to other extraction methods, the oil extraction from kiwifruit seeds using UAE with ethanol presented good performance for extraction yields and high efficiency of extraction. The extraction technique investigated showed high extraction rates and short time of extractions.

The extraction oil yields obtained were between $19 \%$ and $33 \%$. The yield of oil extracted by UAE with ethanol increased $40 \%$ by increasing the temperature ( 293.15 to $333.15 \mathrm{~K}$ ), at $60 \mathrm{~min}$ of extraction. The maximum ultrasound power leads to a considerable increase of extraction yield just at $333.15 \mathrm{~K}$.

Concerning the kinetics model that this work proposes, there is a good agreement between experimental and predicted values using a second-order kinetic model.

The oils extracted by UAE and other different methods presented similar fatty acid profiles with $95 \%$ of C: 18 , and linolenic acid levels of around $60 \%$ of the total fatty acids.

As a result, the kiwifruit seeds can be a good source of oil due to their abundant oil content 
and, at the same time, the oil is rich in fatty acids and tocopherols, proposing a noble use of kiwifruit seed oil at food, nutraceutical, pharmaceutical and cosmetic industries formulations. In general, this work also points the very propitious composition of kiwifruit seed oil, the potential of the use of ethanolic extraction methods to obtain it and a good alternative of valorize and utilize condemned kiwifruits waste.

\section{RESUMO}

\section{EXTRAÇÃO AUXILIADA POR ULTRA-SOM DE ÓLEO DE KIWIFRUIT (ACTINIDIA DELICIOSA) SEMENTES}

Neste estudosão relatados os dados e a modelagem cinética experimental para extração de óleo de sementes de kiwis empregando extração com etanol assistida por ultrassom (EAU). O perfil de ácidos graxos, o tocoferol e o teor total de lipídios no óleo obtido foram determinados. As variáveis temperatura e potência aplicada com o ultrassom foram investigadas com base nos rendimentos da extração do óleo usando um planejamento experimental composto central. Os rendimentos globais obtidos foram comparados aos da extração convencional em Soxhlet com $\mathrm{n}$-hexano e com etanol. As extrações apresentaram altas taxas com rendimento geral variando entre 19 e $33 \%$, e os rendimentos de extração aumentaram com a temperatura. O perfil de ácidos graxos apresentou alto teor de ácido ômega-3 (63,20\%) e o teor de vitamina E foi de 14,97 $\pm 0,38$ $\mathrm{mg} / 100 \mathrm{~g}$ de óleo, sendo o $\gamma$-tocoferol correspondente a $49 \%$ do tocoferol total. Um modelo cinético de segundo ordem foi aplicado para descrever o processo de extração assistida por ultrassom em diferentes condições. Os resultados numéricos foram comparados com os rendimentos de extração experimental e apresentaram boa correlação. A técnica de extração investigada mostrouse adequada para a extração de óleo de sementes de kiwifruit, demonstrando o grande potencial de óleo de kiwi obtido por EAU.

\section{REFERENCES}

1 Abdullah, M., Koc, A.B., 2013. Kinetics Of Ultrasound-Assisted Oil Extraction from Black Seed (Nigella Sativa). J. Food Proc. Preservation 37, 814-823.

2 Bligh, E.G., Dyer, W.J., 1959. A Rapid Method of Total Lipid Extraction and Purification. Can. J. Biochem. Phys. 37, 911917.

3 Coelho, R., Kanda, L.R., Hamerski, F., Masson, M.L., Corazza, M.L., 2015. Extraction of Kiwifruit Seed (Actinidia Deliciosa) Oil Using Compressed Propane. J. Food Process Eng. (In Press).

4 De Melo, M., Silvestre, A., Silva, C., 2014. Supercritical fluid extraction of vegetable matrices: applications, trends and future perspectives of a convincing green technology. J. Supercrit. Fluids 92, 115-176.

5 Fang, X., Wang, J., Wang, Y., Li, X., Zhou, H., Zhu, L., 2014. Optimization of ultrasonic-assisted extraction of wedelolactone and antioxidant polyphenols from Eclipta prostrate $L$ using response surface methodology. Sep. Purif. Technol. 138, 55-64.

6 Fiorentino, A., D’Abrosca, B., Pacifico, S., Mastellone, C., Scognamiglio, M., Monaco, P., 2009. Identification and assessment of antioxidant capacity of phytochemicals from kiwi fruits. J. Agr. Food Chem. 57, 4148-4155.

7 Goula, A.M., 2013. Ultrasound-assisted extraction of pomegranate seed oil-Kinetic modeling. J. Food Eng. 117, 492498.

8 Hamdan, S., Daood, H.G., Toth-Markus, M., Illés, V., 2008. Extraction of cardamom oil by supercritical carbon dioxide and sub-critical propane. J. Supercrit. Fluids 44, 25-30.

9 Horwitz, W., Latimer, G.W., 2005. Official methods of analysis of AOAC International. AOAC International, Gaithersburg, Md. 
10 Illés, V., Daood, H., Perneczki, S., Szokonya, L., Then, M., 2000. Extraction of coriander seed oil by $\mathrm{CO}_{2}$ and propane at super and subcritical conditions. J. Supercrit. Fluids 17, 177-186.

11 Knorr, D., Ade-Omowaye, B., Heinz, V., 2002. Nutritional improvement of plant foods by non-thermal processing. Proceedings of the Nutrition Society 61, 311-318.

12 Lespérance, F., Frasure-Smith, N., St-André, E., Turecki, G., Lespérance, P., Wisniewski, S.R., 2011. The efficacy of omega-3 supplementation for major depression: a randomized controlled trial. J. Clinical Psychiatry 72, $1054-1062$.

13 Li, T., Qu, X.-y., Zhang, Q.-a., Wang, Z.-Z., 2012. Ultrasound-assisted extraction and profile characteristics of seed oil from Isatis indigotica Fort. Ind. Crops Prod. 35, 98-104.

14 MatthauS, B., Ozcan, M.M., 2011. Fatty acids, tocopherol, and sterol contents of some Nigella species seed oil. Czech. J. Food Sci. 29, 145-150.

15 Pederssetti, M.M., Palú, F., Da Silva, E.A., Rohling, J.H., Cardozo-Filho, L., Dariva, C., 2011. Extraction of canola seed (Brassica napus) oil using compressed propane and supercritical carbon dioxide. J. Food Eng. 102, 189-196.

16 Saxena, D.K., Sharma, S., Sambi, S., 2011. Kinetics and thermodynamics of cottonseed oil extraction. Grasas y Aceites $62,198-205$.

17 Shalmashi, A., 2009. Ultrasound-assisted extraction of oil from tea seeds. J. Food Lipids 16, $465-474$.

18 Simopoulos, A.P., 2002. Omega-3 fatty acids in inflammation and autoimmune diseases. J. Am. College Nutrition 21, 495-505.

19 Stevenson, D.G., Eller, F.J., Wang, L., Jane, J.-L., Wang, T., Inglett, G.E., 2007. Oil and tocopherol content and composition of pumpkin seed oil in 12 cultivars. J. Agr. Food Chem. 55, 4005-4013.

20 Tasioula-Margari, M., Okogeri, O., 2001. Simultaneous determination of phenolic compounds and tocopherols in virgin olive oil using HPLC and UV detection. Food Chemistry 74, 377-383.

21 Van Hoed, V., De Clercq, N., Echim, C., Andjelkovic, M., Leber, E., Dewettinck, K., Verhé, R., 2009. Berry seeds: a source of specialty oils with high content of bioactives and nutritional value. J. Food Lipids 16, 33-49.

22 Zhang, Z.-S., Wang, L.-J., Li, D., Jiao, S.-S., Chen, X.D., Mao, Z.-H., 2008. Ultrasound-assisted extraction of oil from flaxseed. Sep. Purif. Technol. 62, 192-198.

\section{ACKNOWLEDGEMENTS}

The authors are thankful to CNPq, CAPES and Fundação Araucária (Brazilian Agencies) for the financial support and scholarships, and the Orgânicos Fruta-Café Company, Curitiba, Brazil) for the kiwifruit supply. 